\title{
Study on Application of the Evaluation Indicator System for the Third-party Environmental Pollution Control
}

\author{
Xu Bingsheng ${ }^{1}$, Guo Huiting ${ }^{1, a}$, Lin Ling $^{1}$, Huang $\operatorname{Jin}^{1}$ and Hou Shan ${ }^{1}$ \\ ${ }^{1}$ China National Institute of Standardization, No. 4, Zhichun Road, Haidian District, 100191 Beijing, China
}

\begin{abstract}
A pilot evaluation indicator system was applied to environmental pollution governance. Four iron and steel enterprises introducing the third-party environmental pollution governance service were selected to carry out the evaluation and application, including sintering flue gas desulfurization and dust removal projects and waste water comprehensive treatment projects to which iron and steel enterprises pay high attention in "the 13th Five-Year Plan" period. Delphi Method was used to grade and quantify each indicator according to experience and determine the validity of scores. Radar charts for the four enterprises were formed based on the weights of Level-2 indicators for comprehensive evaluation and quantification of basic capability, facility operation, technical economy, environmental benefits and management level, and conclusions related to advantages and disadvantages of these enterprises were drawn. This research supplies a scientific method for evaluating the effect of environmental pollution control by third-party enterprises.
\end{abstract}

\section{Introduction}

Environmental pollution control is deemed to a public welfare behaviour or enterprises' own behaviour, which is hard to motivate the enthusiasm of pollution treatment without financial incentives. Furthermore, it is difficult to distinguish the responsibility between the pollution emitter and the pollution controller. Therefore, it is inappropriate to ignore the market behaviour which has a great influence on the pollution control effect. In other words, it is necessary to build an evaluation indicator system to encourage the mode of third-party environmental pollution control and to promote the environmental protection industry development by market adjustment.

The relatively chaotic market of environmental pollution control is mostly caused by the lack of scientific effect evaluation and reasonable entrance system. The control effect of the project of pollution treatment is objective to measure, and supporting policies is short of scientific basis. Therefore, it is significant to discuss the evaluation method to stimulate the motivation of the introduction of the third party governance of environmental pollution by enterprises with pollutants over-discharged.

\section{Definition Of Evaluation Indicators}

Indicator system is established for evaluation of the third-party governance over environmental pollution. 26 Level-2 indicators were chosen to evaluate the environmental pollution control effects, which include the basic capability of an enterprise, operation of facilities, technical economy, environmental benefits and management level [1,2].

Specifically speaking, basic capability fundamentally exhibits the core competitiveness of the third-party control service enterprise for environmental pollution, giving emphasis on its value, heterogeneity, inimitability, irreplaceability as well as other features. Due to limited scales and inadequately developed basic capabilities in most Chinese enterprises, cultivating such capabilities of environmental service enterprises should be given priority [3]. Through experts' researches and business visits, the basic capability of an enterprise is determined by focusing on the investigation of the crew size, enterprise scale, social credit, financial condition, proportion of professional technicians, technological innovation ability and investment \& financing capacity of the enterprise for environmental pollution service. Statistical evaluation [4] can be performed to assess the basic enterprise capability before introducing the project. Among which, the crew size $(\mathrm{C} 1)$ is a critical qualitative element to the basic enterprise capability, which should be scored based on actual conditions of the enterprise. For the operation and service organization of an environmental protection facility, the number of operators on the operating site greater than or equal to 40 should be assessed as excellent, while that number greater than 10 should be determined as basically qualified. The enterprise scale (C2) is a critical qualitative element to the basic capability and core competitiveness of an enterprise, which can reflect the professional competence of an environment enterprise when providing the third-party control service, and is considered by a polluter when a pollution control enterprise is commissioned or entrusted to operate an

*Corresponding author: a author@e-mail.org 
environmental protection project. The optimal scale matching should be made according to actual conditions of the enterprise, and the active role of the scale played in the course of business expansion should be taken into account as well from the perspective of promoting longterm development of the enterprise. The social credit indicator (C3) indicates the comprehensive assessment of the previous basic business capability of a pollution service enterprise. The credit rating given by public opinions can objectively measure the credit assurance an enterprise bringing to a polluter when providing environmental control service and such indicator is one of the core indicators considered by the polluter under a commissioned control or an entrusted operation mode. The financial condition (C4) can reflect the capability of a pollution service enterprise to deal with risks in providing project implementation tasks. Good financial condition of an enterprise is an important precondition indicator for introducing environmental protection enterprises to provide the entire life cycle including the project design, investment, construction and operation. The proportion of professional technicians (C5) can be used as a quantitative indicator, reflecting the professional features of environmental pollution control services, and the capability of a pollution control enterprise to provide technical supports to pollution discharge enterprises in the process of construction, operation and maintenance. The technological innovation ability of an enterprise (C6) can qualitatively reflect the potential capability of the environmental protection service enterprise to control pollution in a scientific way and improve the level of controlling pollution. The pollution discharge enterprises hope to enhance the effectiveness of control by introducing hightech pollution control service enterprises; meanwhile it is an important supplement to improve the overall level of pollution discharge enterprises. Investment \& financing capacity (C7) is an important indicator to measure environmental service enterprises. Pollution discharge enterprises want to introduce pollution control enterprises for two purposes: one is to professionalize the pollution control, and the other is to share project construction and operation costs and share achievements and policy dividends of pollution control by introducing pollution control enterprises. Pollution discharge enterprises hope to get better pollution control effect with fewer costs, at the same time, through investment and financing to obtain the return of environmental protection benefits.

The effect of the operation of facilities refers to the quality for environmental pollution control process by the third party, directly proportional to the service value of an environmental protection service enterprise. Through the monitoring of facilities operation and the setting of evaluation indicators, it can positively promote the quality of pollutant control facilities, and take the important supporting function of pollutant control facilities on enhancing pollution prevention and control as well as industrial core competitiveness into effect, to promote healthy development of the environmental protection industry. Under the condition of meeting environmental emission requirements and safe operations, the equipment shall be energy-saving and accordant with the basic requirements for reasonable resource allocation, environmental protection as well as social and economic sustainable development. Among which, The facility energy consumption level (C8) can reflect the energy-saving effect of the facility and accessory equipment, and it is especially important to reduce costs and save resources. The facility energy consumption level depends on the specific pollutant type to be treated and pollutant control equipment to be selected. The facility water consumption level (C9) can reflect the water-saving effect of the facility and its accessory equipment, and it is especially important to reduce costs and save water resources. The facility water consumption level depends on the specific pollutant type to be treated and pollutant control equipment to be selected. The equipment availability (C10) indicates the actual availability of various types of equipment provided in the pollution control project for the purpose of measuring the failure rate of the equipment provided in the pollution control project and the normal operating condition of the supporting equipment. Equipment operation ratio $(\mathrm{C} 11)$ refers to the percentage of the normal operating period of the pollution control equipment in the total operating period of the production process every year, and it is an important index for measuring the actual operating condition of the pollution control project in the production process. Facility and equipment service life (C12) refers to the normal service life of single equipment in the pollution control service process, and it is an important index for measuring the project sustainability and the normal operating period of the overall project.

Technical economy refers to the cost control for environmental pollution control service by a third party, inversely proportional to the service value of the environmental protection service enterprise. Through calculation of the costs required to carry out environmental pollution control services and setting of economic assessment index, it is an important reference of cost accounting for a pollution discharge enterprise; it can also remind the environmental pollution service enterprise to pay attention to the cost which is a core competitive factor while improving the technology, reducing cost, and increasing the pollution prevention and control level, involving the operation maintenance cost, manual labour cost, etc. required to pay during operation for maintaining the normal operation of the pollution control project within the project cycle. The investment cost (C13) of environmental pollution control service aims at atmosphere, wastewater or solid pollutant is required by the pollution discharge enterprise in unit pollutant, as an important index for assessing the investment level of the environmental pollution control project, can objectively measure the basic capability of each environmental pollution control service enterprise participating in the bid. Based on one year, the maintenance cost (C14) arising from the operating process of the project is considered and measured. Engineering maintenance is an important precondition of guaranteeing normal construction of the project and effectively controlling pollutant discharge, and the 
operation service level of the environmental pollution control enterprise is measured through calculation of the maintenance cost required every year, providing reference for the polluter to introduce options. Based on one year, the labour cost $(\mathrm{C} 15)$ arising from the operating or maintenance process of the project is considered and measured. Annual labour cost is a cost necessarily paid for guaranteeing normal operation or maintenance of the environmental pollution control project, and the supporting labour level provided by the environmental pollution control enterprise for the project is assessed through calculating the labour cost required every year, providing reference for the polluter to introduce options. Floor area $(\mathrm{C} 16)$ refers to the floor area for the desulfuration, dust removal, denitration, wastewater control and solid waste disposal equipment (including control room, equipment and accessory equipment and byproduct disposal equipment) when the production process generating pollution is provided with relevant pollution control facilities. Available Byproducts (C17) may be generated in the process of disposing pollutants, such as sulfuric acid and other byproducts generated in the wet flue-gas desulfurization, and efficient utilization of byproducts can generate considerable benefits for pollution discharge enterprises and pollution control third-party enterprises, and reduce costs.

Environmental benefits, also an important first-grade index for measuring the environmental pollution control service level, indicate the result quality of environmental pollution control by the third party, directly proportional to the service value of the environmental protection service enterprise. When the discharge pollution enterprise introduces the third party enterprise for environmental pollution control, it is necessary to strictly define the initial environmental pollution conditions and pollution discharge conditions after control required to be disposed as agreed by both parties in the context of the environmental service management contract. When the environmental benefits of the pollution control enterprise are assessed, it is necessary to provide scientific, reasonable pollutant monitoring technology, method and equipment, and the environmental benefits brought about to the polluters by the pollution control enterprises are assessed through objective data. Among which, According to different industries, the discharge standards (C18) are considered for pollutant types strictly in accordance with the national standards of discharge limits on atmosphere, sewage and solid pollutants. Improving the environment around the pollution discharge factory or park $(\mathrm{C} 19)$ is an important index for measuring environmental pollution control service results, and also a concentrated and extended reflection of the environmental benefits generated. The control effect of environmental pollution control service is not only to make the pollutant discharge concentration of the factory or park reach the standard, but also to consider the improvement of the surrounding ecological environment. Removal rate of pollutants (C20) indicates the control ability and efficiency during the process of control of contractual environmental management for environmental pollution control services and refers to unit removal rate of pollutants and removal rate of secondary pollutants of air pollutants and water pollutants.

During the process of the evaluation, management provided by a pollution control service enterprise shall be taken into account, especially the management, which concerns the effectiveness of environmental pollution control project, during the construction, operation and service processes of pollution control projects. Hence, operating enterprise shall establish a uniform management system. Pollution control enterprise is required to have complete rules and regulations (C21), corresponding environmental management organizations, training schemes and records as well as emergency response plans and drill records. Online monitoring (C22) is the essential precondition for making sure that environmental pollution control service is effective in real time, and the control reaches standard. Environmental pollution control project shall be equipped with automatic online monitoring system to detect problems in real time during the process of control. Secondary pollution control measure (C23), representing complementary safety measures for problems occurring to the environmental pollution control so as to ensure that pollutants are controlled effectively, is vital to pollution discharge enterprises. Service timeliness (C24) includes the reaction speed of service provider towards problems when pollution discharge enterprises come up with requirements, and the time consumed and benefits gained when solving problems. Service quality (C25) includes that firstly, whether problems are solved successfully or not, only when they are solved can service be meaningful; secondly, the quality of problemsolving, which can be done through observing the time of normal operation of the equipment, shall be taken into consideration; in addition, service provider's attitude as well as complete disciplines and regulations shall be considered. Ledger records of operation, overhaul and maintenance shall be complete; inspection analysis report and chemical analysis records shall be complete and detailed; the ledger shall be complete for equipment; technical data shall be filed; and safe and civilized production shall meet the requirements of safe, stable and normal operation of system. The satisfaction of service purchaser (C26) is a reflection of purchaser's recognition on environmental pollution control services. The satisfaction of service purchaser can be measured through evaluation of clients, complaints and its frequency as well as recommendation on market.

\section{Determination of Indicator Evaluation Scores}

Incommensurability and contradiction among indicators are unavoidable problems during the establishment of multi-objective decision-making indicator system. Incommensurability among indicators means that indicators cannot be compared directly because there is no unified measure standard. Therefore, it is required to normalize property values of specific indicators before comprehensive evaluation with the indicator system, 
that's, indicators should be converted to those in a comparable range [5-6]. Methods of normalization vary with the type of evaluation indicators.

26 Level-2 indicators were scored from 0 to 10 . Each one was scored by 7 experts based on indicator compliance. We invited experts to assess four service enterprises or projects A, B, C and D introducing environmental pollution governance facilities in the iron and steel industry on site, including sintering flue gas desulfurization and dust removal projects and waste water comprehensive treatment projects, or submitted materials to them for analysis. Detailed scores after averaging are shown in Table 1 as below.

It can be seen that the four environmental pollution governance projects have been recognized by experts in terms of discharge compliance, removal rate of pollutants, automatic online monitoring system setting and secondary pollution control measures, and met policies, regulations and standards related to pollution treatment in China.

Table 1. Overall Rank and Weights of Evaluation Indicators

\begin{tabular}{|c|c|c|c|c|}
\hline Indicators & $\mathrm{A}$ & $\mathrm{B}$ & $\mathrm{C}$ & $\mathrm{D}$ \\
\hline $\mathrm{C} 1$ & 7.3 & 6.5 & 8.5 & 7.1 \\
\hline C2 & 7.9 & 7.2 & 8.8 & 8.1 \\
\hline C3 & 6.5 & 9.2 & 5.4 & 7.9 \\
\hline C4 & 9.2 & 9.4 & 9.1 & 9.1 \\
\hline C5 & 8.8 & 8.5 & 7.9 & 9.0 \\
\hline C6 & 8.9 & 7.1 & 8.2 & 7.5 \\
\hline C7 & 9.1 & 8.2 & 8.4 & 6.2 \\
\hline C8 & 9.2 & 9.4 & 9.1 & 8.9 \\
\hline C9 & 9.1 & 9.3 & 8.3 & 6.5 \\
\hline C10 & 10 & 10 & 10 & 10 \\
\hline C12 & 10 & 10 & 10 & 10 \\
\hline C13 & 9.2 & 9.4 & 9.4 & 9.1 \\
\hline C14 & 8.4 & 8.1 & 8.9 & 9.2 \\
\hline C15 & 8.7 & 9.3 & 8.7 & 8.1 \\
\hline C16 & 7.3 & 8.9 & 7.9 & 8.3 \\
\hline C17 & 9.2 & 7.7 & 8.8 & 8.9 \\
\hline C18 & 10 & 10 & 10 & 10 \\
\hline C19 & 8.7 & 8.9 & 9.2 & 9.1 \\
\hline C20 & 10 & 10 & 10 & 10 \\
\hline C21 & 9.2 & 9.5 & 9.2 & 9.7 \\
\hline C22 & 10 & 10 & 10 & 10 \\
\hline C23 & 10 & 10 & 10 & 10 \\
\hline C24 & 9.2 & 9.0 & 8.7 & 7.5 \\
\hline C25 & 9.5 & 8.8 & 8.1 & 7.9 \\
\hline & 8.7 & 8.9 & 8.1 & 8.3 \\
\hline
\end{tabular}

C1-C26 represents for Number of staff, Enterprise Scale, Market Investment and Financing Capacity, Social Credit, Financial Position, Proportion of Professionals, Enterprise Technical Innovation Capability, Facility Energy Consumption, Facility Water Consumption, Equipment Availability, Equipment Operation Rate, Facility Service Life, Pollutant Treatment Cost, Annual Maintenance Cost, Annual Labor Cost, Floor Area, By-product Utilization, Discharge Compliance, Improvement of Surrounding Environment, Removal Rate of Pollutants, Safe Operation Rules and Regulations, Automatic Online Monitoring, Secondary Pollution Control Measures, Service Timeliness, Service Quality and Normalization and Service Buyer Satisfaction, respectively.

\section{Comprehensive Evaluations and Analysis of Enterprises}

Based on the above data, the four enterprises A, B, C and $\mathrm{D}$ can be measured from five aspects of basic capability, facility operation, technical economy, environmental benefits and management level. We can obtain scores of five Level-1 indicators of each enterprise according to the weights of Level-2 indicators, namely, the scores provided by experts. The radar charts of the four enterprises are shown as below.

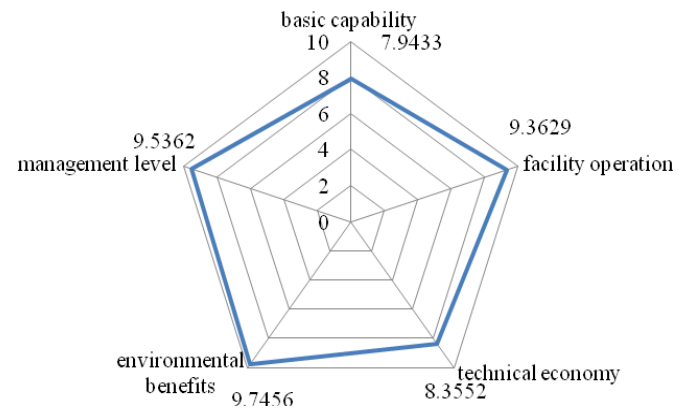

Figure 1. Comprehensive Evaluation of Enterprise A.

According to Fig.1, Enterprise A is relatively outstanding in terms of various abilities and shows a great advantage in environmental benefits in the comprehensive evaluation, but its basic capability and technical economy need to be enhanced. According to Fig.2, Enterprise B is excellent in terms of management level, facility operation and environmental benefits in the comprehensive evaluation, but its basic capability and technical economy are relatively poor.

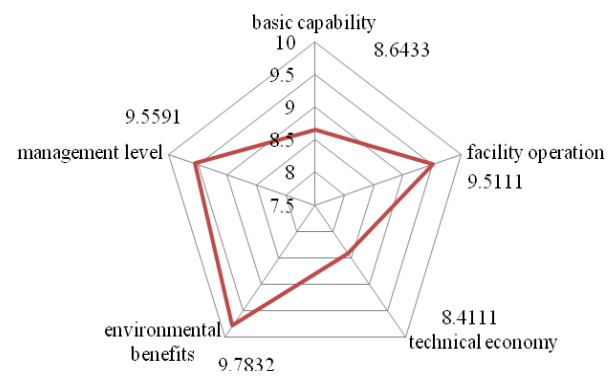

Figure 2. Comprehensive Evaluation of Enterprise B.

According to Fig.3, C's environmental benefits are relatively outstanding in the comprehensive evaluation. The assessment result of its basic capability turns out to be the worst. And its management level, facility operation and technical economy need to be improved.

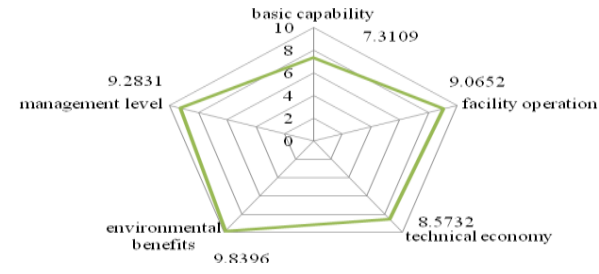

Figure 3. Comprehensive Evaluation of Enterprise C. 
According to Fig.4, Enterprise D's environmental benefits are relatively outstanding in the comprehensive evaluation. Its basic capability, management level, facility operation and technical economy need to be improved.

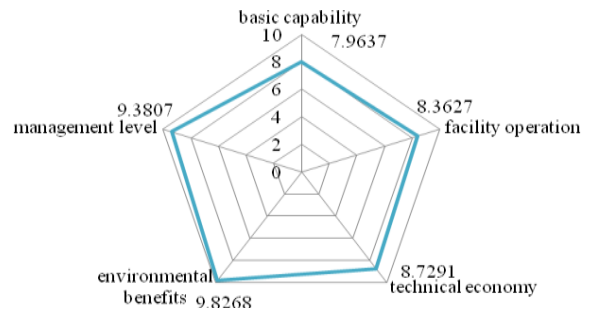

Figure 4. Comprehensive Evaluation of Enterprise D.

\section{Conclusions}

The third-party environmental pollution governance evaluation can increase the pollution governance level of enterprises, promote the application of relevant technologies in pollution treatment projects, and stimulate enterprises with high service level to stand out from market competition, thus to achieve the survival of the fittest, and improve pollution prevention and control capability and governance efficiency. In this paper, a pilot evaluation indicator system was applied to environmental pollution governance on the theoretical basis of grey correlation analysis. Four iron and steel enterprises introducing the third-party environmental pollution governance service were selected for evaluation. The research methods for evaluating comprehensive indicators of the third-party environmental pollution governance were defined with typical third-party environmental pollution transformation projects as a start, which cover important links of project financing, operation mode, responsibility defining, payment mechanism and effect monitoring related to pollution treatment service, and radar charts for the four enterprises for comprehensive evaluation and quantification in terms of basic capability, facility operation, technical economy, environmental benefits and management level were formulated with conclusions drawn on advantages and disadvantages of these enterprises. The research method in this paper can be used to solve problems such as unclear responsibility, unsound mode, nonstandard service and unreasonable assessment during the third-party environmental pollution governance.

\section{Acknowledge}

This work was supported by the Surplus Foundation of the study on standard system of ecological civilization. (Grant No. 542017Z-5454).

\section{References}

1. A. Mofarrash, T. Husain, J MATER CYCLES WASTE 15,1 (2013)
2. H.T. Bai, H.Z. Wang, H. Xu, T. Zhu, J ZHEJIANG UNIV-SC A 11,5(2011)

3. Z.H.Yu, X. F, W.Y. Li, S. P, Y.X. Lu, ENVIRON SCI TECHNOL (2016)

4. L. He, Northern Environment (2013)

5. L.K. Govorova, T.A. Makarova, A.B. Lolaev, MIN PROC EXT MET REV ,1-4(1995)

6. A. Cervone, D.Z. Romito, E. Santini, International Conference on Clean Electrical Power, (2001) 